\title{
The Empirical Research on Knowledge Diffusion Mechanisms in Global Production Networks
}

\author{
Jinbo Wang \\ School of Economics, Xiamen University, Xiamen, China, Wangjb168@ 163.com
}

\begin{abstract}
Knowledge diffusion mechanism in the global production networks(GPNs) is a model for the dissemination of knowledge in the networks. With such backgrounds, based on 143 samples of Chinese manufacturing firms, it carries out the empirical research on Knowledge Diffusion Mechanisms in Global Production Networks, and the results show that: those firms which embedded in GPNs should be familiar with knowledge diffusion model and channels in GPNs as soon as possible, so they can get much knowledge from GPNs.
\end{abstract}

Keywords: Global Production Networks, Knowledge Diffusion Mechanisms, Empirical Research.

\section{Introduction}

With the wave of industrial upgrading and transferring, multinational firms set the different product segments of the same value chain at the lowest cost place of the production in the world according to the situation of the different comparative advantages and competitive advantage of countries or regions, to form the international integration of production systems as a link to global production networks (GPNs). To some degree, the firms in GPNs linked to cooperation and engaged in technological innovation to- gether, and knowledge diffusion plays a very crucial role in this process of cooperation. Knowledge as the most important factor of production in presently, its value is reflected in its extensive and effective application, and knowledge diffusion is one of the best measures to realize the value of knowledge. Especially in the GPNs, although the process of knowledge diffusion is relatively slow and costly, but the knowledge diffusion mechanism in GPNs can makes the knowledge have a wider, higher level applications possibly, and such applications can further promote technology innovation capability in the entire GPNs.

\section{Theories of Knowledge Diffusion Mechanisms}

Because of the importance of knowledge diffusion mechanism, more and more scholars concerned about the research on this issue. Domestic and foreign scholars mainly do knowledge diffusion mechanism research from the spillover theory, innovation diffusion theory, imitation theory, communication theory, organizational learning theory.

\subsection{Spillover theory}

Spillover is a behavioral result of the person or organization in a certain social environment. Spillover exists in all areas of society, and knowledge areas are also 
widely exist spillover. The nature of knowledge spillover is involuntary diffusion of knowledge, because after knowledge created, its innovators and other persons all can use it in a low cost, resulting in the social marginal benefit of knowledge greater than the private marginal benefit of knowledge, namely, there is spillover effect in this process. Such spillover knowledge includes the organization information, technology, skills, management model, and the destination of spillover knowledge is other organization or market. In reality, during an organization communication with others in economic and business areas, the knowledge would naturally spillover.

One of the main research areas of knowledge spillover is the knowledge spillover between multinational firms. By studying technology and productivity spillover in local caused by multinational firms establish a subsidiary in another country, Kokko(1992) thinks the involuntary diffusion of technology which caused by technology transfer will result in the promotion of local technology and the improvement of local productivity, and it is an external effect of technology diffusion. Kokko also believes that technology spillovers occur mainly from two aspects: firstly, demonstration, imitation and diffusion, the second is competition. Therefore, the study of knowledge spillover theory has a considerable promoting effect in the research on knowledge diffusion mechanism.

\subsection{Innovation diffusion theory}

Innovations diffusion theory is that seeks to explain how, why, and at what rate new ideas and technology spread through cultures. Rogers(1962) popularized this theory in his book Diffusion of Innovations. In this book says that diffusion is the process by which an innovation is communicated through certain channels over time among the members of a social system. The innovation must be widely adopted in order to self-sustain. Within the rate of adoption, there is a point at which an innovation reaches critical mass. Diffusion of Innovations manifests itself in different ways in various cultures and fields and is highly subject to the type of adopters and innovation-decision process. With successive groups of consumers adopting the new technology, its market share will eventually reach the saturation level. In mathematics the $S$ curve is known as the logistic function.

\subsection{Imitation theory}

Posner(1961) proposed innovation and imitation theory(also known as the Technological Gap Theory). The theory is that technical is actually a knowledge production factor, innovation country successful research new products, with leading technology advantage, innovation country export of such new products to imitation country. However, with patent right transfer, technical cooperation, foreign investment and development of international trade, the leading technology of innovation country gradually spread to imitation country, then imitation country began to produce these products and reduce imports of these products with use own advantages of low labor costs, after that innovation country gradually losing export market for these products. But, innovation country will innovative and update technologies and processes for producing new generation of products, thus innovation country will forming a new round of technological advantages, and export new generation of products to imitating national again, so the cycle as well as infinite. From the perspective of knowledge, technological innovation is actually knowledge innovation, therefore, the process of technology transfer between technological gap countries is essentially a knowledge transfer, knowledge diffusion process. 
Overall, imitation is not a passive activity, it has a cost. Entrepreneurs need to determine whether to imitate and use of existing knowledge, because the generation of new knowledge have the byproduct nature of learning by doing model. In each period there are certain industrial knowledge stocks in networks, entrepreneurs may invest resources to imitate this knowledge, and it will extend the existing industrial knowledge stocks at the process of learning by doing.

\subsection{Communication theory}

Krone, Jablin \& Putman(1987) proposed communication theory. After studying the process of organization's communication, they believe that the basic elements of the process of communication between two individuals include: sender, encoding mode, communication channel, the information transmission, decoding mode, recipient, and implication given by decoded information.

Communication theory becomes an important method of research knowledge sharing and diffusion with the gradual deepening of research. Hendriks(1999) pointed out, knowledge sharing and diffusion is a process of communication. Also he believes that knowledge can't freely pass which is not like commodities, and when a person shares and diffuses knowledge learned from others, he must have refactoring actions of knowledge. Therefore, knowledge sharing and diffusion necessarily involves two entities: the owner side and the demand side of knowledge. The owner side of knowledge provides knowledge by the way of speech, writing, or other forms, while the demand side of knowledge must be aware of this expression, and identify and understand the knowledge by imitation, listen, read or other ways. Jim Botkin(2000) thinks that knowledge sharing and diffusion is the core of network management model, knowledge sharing and diffusion is com- munication in simply. But in order to achieve the goal of communication, there must be connection between them. Therefore, knowledge sharing and diffusion is connection and communication among people. Holtham \& Courtney(2001) pointed out that knowledge sharing is a process of communication, when someone learns knowledge(knowledge sharing), he must have rebuilt behavior and the necessary knowledge so that he can complete the knowledge transfer.

\subsection{Organizational learning theory}

In 1978, Chris Argyris \& Donald A. Schon published a book: Organizational Learning, after that, the academic study of organizational learning is increasing. Especially in recent years, the enterprise network organizations develop very rapidly(such as the GPNs, strategic networks, inter-organizational networks), so more and more enterprises organize production and trading activities with adopting the way of learning and cooperation between enterprises. Therefore, the research on the theory of the enterprise network organization becomes a hot field.

Organizational learning not only is the process of personal and collective learning, but also is the process of knowledge diffusion in networks. Organizational learning needs individual learning, at the same time it is inseparable from the individual accessing, sorting, processing, and remembering information, and until it becomes organizational knowledge. Organizations can accumulate knowledge to improve their learning ability from learning process, that is "Learning by Doing". But the learning process is inseparable from the members of the organization, and every individual is carrier of the organizational learning. People in organization constantly sense the environment, access to relevant information from the environment. After treatment, the information becomes the personal knowledge 
ultimately. With the people movement of intra-organization or inter-organizations, it will promote the diffusion, interpretation, and memory of personal knowledge. Lastly personal information will gradually become a valuable organizational knowledge to the organization. The improvement of organizational learning capabilities requires not only "learning by doing" and also requires "Learning by Cooperation", that is obtaining knowledge from networks with other organizations to improve learning ability. For example, enterprises always get some corresponding new knowledge by communication with customers, suppliers, distributors, consultants and even competitors, , while other organizations in communication are also able to get the knowledge which they need. Whether this knowledge is explicit knowledge or tacit knowledge, it will eventually become the organization's own knowledge.

\section{The Empirical Research on Knowledge Diffusion Mechanisms}

We collected our data by the means of questionnaire. In the last, 143 valid questionnaires were collected. The questionnaire is shown as table 1 . The level of measurement in the questionnaire is carried out Likert scale using five Likert items, five scales were used to strongly disagree, disagree, neutral, agree and strongly agree.

Tab. 1: The measure questions of knowledge diffusion mechanism

\begin{tabular}{|c|c|c|}
\hline Measurement Index & Question No. & Question \\
\hline \multirow{6}{*}{$\begin{array}{l}\text { Firm's internal fac- } \\
\text { tors }\end{array}$} & 1.1 & Your firm has close relationship with other firms in GPNs. \\
\hline & 1.2 & $\begin{array}{l}\text { Your firm has a strong ability to knowledge absorption, digestion, and } \\
\text { effective use of knowledge. }\end{array}$ \\
\hline & 1.3 & Your firm has a strong desire to participate in knowledge diffusion. \\
\hline & 1.4 & $\begin{array}{l}\text { Your firm's decisions are usually made by senior managers, including } \\
\text { participation in knowledge diffusion. }\end{array}$ \\
\hline & 1.5 & The environment of your firm is conducive to knowledge diffusion. \\
\hline & 1.6 & $\begin{array}{l}\text { Employees in your firm can easily accept new knowledge due to men- } \\
\text { tal qualities, knowledge base and evaluation capacity. }\end{array}$ \\
\hline \multirow{4}{*}{ GPNs factors } & 2.1 & $\begin{array}{l}\text { Most firms in GPNs can make directly technological exchanges and } \\
\text { knowledge sharing between enterprises. }\end{array}$ \\
\hline & 2.2 & $\begin{array}{l}\text { Cooperative enterprises in GPNs can easily reach agreements without } \\
\text { complex negotiation and contract, because there are high degree of } \\
\text { trust in knowledge sharing between them. }\end{array}$ \\
\hline & 2.3 & The knowledge transfer smoothly in GPNs. \\
\hline & 2.4 & Knowledge diffusion is very fast and very effective in GPNs. \\
\hline \multirow{5}{*}{$\begin{array}{l}\text { Diffusion model } \\
\text { and channels }\end{array}$} & 3.1 & $\begin{array}{l}\text { Core firms can use technology and scale advantages to research, then } \\
\text { rapidly get new knowledge. }\end{array}$ \\
\hline & 3.2 & Core firms are willing to take knowledge diffusion with other firms. \\
\hline & 3.3 & $\begin{array}{l}\text { Firms in GPNs can access to knowledge through the transaction (such } \\
\text { as the purchase of intellectual property) under market mechanism. }\end{array}$ \\
\hline & 3.4 & $\begin{array}{l}\text { There are knowledge transferring from one knowledge source subject } \\
\text { to many firms in knowledge diffusion of GPNs. }\end{array}$ \\
\hline & 3.5 & Firms can spread new knowledge to other firms after receiving it. \\
\hline \multirow{3}{*}{$\begin{array}{l}\text { Knowledge diffu- } \\
\text { sion results }\end{array}$} & 4.1 & $\begin{array}{l}\text { Your firm can absorb a lot of knowledge from partners through active- } \\
\text { ly participation in knowledge diffusion. }\end{array}$ \\
\hline & 4.2 & $\begin{array}{l}\text { Each firm can get almost same knowledge during they learn technical } \\
\text { knowledge of core firms together. }\end{array}$ \\
\hline & 4.3 & Core firms are willing to strengthen knowledge diffusion in GPNs. \\
\hline
\end{tabular}


Due to the knowledge gained through questionnaires spread of outcomes data is sorted discrete data exists, therefore, this study used to sort the data model for empirical analysis, model specific form as follows:

Assume $y^{*}=x^{\prime} \beta+\phi\left(\mathrm{y}^{*}\right.$ is unobservable), the selected rules:

$$
y=\left\{\begin{array}{cc}
0 & y^{*} \leq r_{0} \\
1 & r_{0} \leq y^{*} \leq r_{1} \\
2 & r_{1} \leq y^{*} \leq r_{2} \\
\cdots & \cdots \\
J & r_{J-1} \leq y^{*}
\end{array}\right.
$$

Among them, $r_{0}<r_{1}<r_{2}<\cdots<r_{J-1}$ are the estimated parameters, known as cutoff points.

In this paper, we select Probit model. We set that independent variables are the mean of firm's internal factors, the mean of GPNs factors and the mean of diffusion model and channels, and dependent variable is each measure question in knowledge diffusion results. We analysis the effect factors of knowledge diffusion in GPNs with Maximum Likelihood estimation method by stata 9.0 , and the results of the analysis is shown in table 2-4.

Firstly, we analyze the effect factors of absorbing knowledge from partners, and the results of the analysis are shown in table 2 .

From table 2, we can find all coefficients are positive which include firm's internal factors, GPNs factors and diffusion model and channels. But, firm's internal factors do not pass the significance test, while GPNs factors is significant in 0.1 significance level, diffusion model and channels is significant in $0.001 \mathrm{sig}$ nificance level, and the coefficient of diffusion model and channels is the biggest one. Therefore, as for absorbing knowledge from partners, our study suggests that the diffusion model and channels are the most important contributing factors, and GPNs factors are also important contributing factors, but firm's internal factors was not significant.

Secondly, we analyze the effect factors of getting almost same knowledge from core firms, and the results of the analysis are shown in table 3.

From table 3, we can find firm's internal factors have no significant effect on getting almost same knowledge from core firms, but GPNs factors and diffusion model and channels have positive significant effect on getting almost same knowledge from core firms while GPNs factors is significant in 0.01 significance level, diffusion model and channels is significant in 0.1 significance level.

Thirdly, we analyze the effect factors of core firms willing to strengthen knowledge diffusion, and the results of the analysis are shown in table 4.

From table 4, we can find firm's internal factors and GPNs factors have no significant effect on core firms willing to strengthen knowledge diffusion, but diffusion model and channels have positive significant effect on core firms willing to strengthen knowledge diffusion.

Tab. 2: The effect factors of absorbing knowledge from partners

\begin{tabular}{l|l|l|l|l|l|l}
\hline Question 4.1 & Coef. & Std. Err. & $\mathrm{z}$ & $\mathrm{P}>|\mathrm{z}|$ & \multicolumn{2}{|c}{$[$ [95\% Conf. Interval] } \\
\hline Firm's internal factors & 0.1158362 & 0.2063154 & 0.56 & 0.574 & -0.2885344 & 0.5202069 \\
\hline GPNs factors & 0.2840379 & 0.1474017 & 1.93 & 0.054 & -0.0048641 & 0.57294 \\
\hline Diffusion model and channels & 1.205262 & 0.2020391 & 5.97 & 0.000 & 0.8092726 & 1.601251 \\
\hline
\end{tabular}


Tab. 3: The effect factors of getting almost same knowledge from core firms

\begin{tabular}{l|l|l|l|l|l|l}
\hline Question 4.2 & Coef. & Std. Err. & $\mathrm{z}$ & $\mathrm{P}>|\mathrm{z}|$ & \multicolumn{2}{|c}{$[95 \%$ Conf. Interval] } \\
\hline Firm's internal factors & -0.1014344 & 0.1921986 & -0.53 & 0.598 & -0.4781368 & 0.275268 \\
\hline GPNs factors & 0.3701382 & 0.1381536 & 2.68 & 0.007 & 0.0993622 & 0.6409143 \\
\hline Diffusion model and channels & 0.3038892 & 0.1717462 & 1.77 & 0.077 & -0.0327272 & 0.6405057 \\
\hline
\end{tabular}

Tab. 4: The effect factors of core firms willing to strengthen knowledge diffusion

\begin{tabular}{l|l|l|l|l|l|l}
\hline Question 4.3 & Coef. & Std. Err. & $\mathrm{z}$ & $\mathrm{P}>|\mathrm{z}|$ & \multicolumn{2}{|c}{ [95\% Conf. Interval] } \\
\hline Firm's internal factors & -0.1229153 & 0.1994297 & -0.62 & 0.538 & -0.5137904 & 0.2679598 \\
\hline GPNs factors & 0.2260372 & 0.1411022 & 1.60 & 0.109 & -0.050518 & 0.5025924 \\
\hline Diffusion model and channels & 1.025059 & 0.1899527 & 5.40 & 0.000 & 0.6527587 & 1.39736 \\
\hline
\end{tabular}

\section{Discussion and conclusion}

Based on the above empirical results, we can find that diffusion model and channels are the main factors which have significant effect on knowledge diffusion in GPNs, because diffusion model and channels have all significant positive effect on the three aspects of knowledge diffusion results, and GPNs factors only have significant positive effect on absorbing knowledge from partners and getting almost same knowledge from core firms, while firm's internal factors have no significant effect on the any aspect of knowledge diffusion results. Therefore, the firms should become familiar with knowledge diffusion model and channels and embedding in knowledge diffusion mechanism in GPNs as soon as possible, so that they can get knowledge as much as possible from GPNs.

\section{Acknowledgements}

This research is supported by Philosophy and Social Science Planning Project of Fujian Province (Grant 2013C013). The authors would like to thank the anonymous reviewers for their valuable suggestions and critique.

\section{References}

[1] M. Y. Jaber, S. K. Goyal, Coordinating a three-level supply chain with multiple suppliers, a vendor and multiple buyers, Int. J. Production Economics, vol. 116, pp. 95-103, 2008.

[2] Hendriks P., Why share knowledge? The influence of ICT on the motivation for knowledge sharing, Knowledge and Process Management, 6(2): 91-100, 1999.

[3] Holtham C. ,Courtney N., Developing managerial learning styles in the context of the strategic application of information and communications technologies, International Journal of Training \& Development, 5(1): 22-34, 2001.

[4] Kokko A., Foreign Direct Investment, Host Country Characteristics and Spillovers, Sweden: the Economic Research Institute, 1992.

[5] Krone K., Jablin F. M., Putman L., Communication theory and organizational communication: multiple perspectives, in Handbook of Organizational Communication, Jablin F. M. et al., eds., Newbury Park: CA Sage Publications, Inc., 1-17, 1987.

[6] Posner M. V., International trade and technical change, Oxford Economic Papers, 13(3): 323-341, 1961. 